\title{
Recurrent Bacterial Meningitis in Paediatrics
}

\author{
Gihad Alsaeed $^{1, ~ *}$, Ibrahim Alsaeed ${ }^{2}$, Mohamed Alsaeed ${ }^{3}$ \\ ${ }^{1}$ Department of Pediatrics, Altakhassussi Hospital, Riyadh, Saudi Arabia \\ ${ }^{2}$ Faculty of Medicine, University of Milan, Milan, Italy \\ ${ }^{3}$ Faculty of Medicine, University of Pavia, Pavia, Italy
}

\section{Email address:}

gehadalsaeed@yahoo.com(G. Alsaeed), ibrahimalsaeed955@gmail.com(I. Alsaeed), Mohamed.alsaeed@universitadipavia.it(M. Alsaeed)

${ }^{*}$ Corresponding author

\section{To cite this article:}

Gihad Alsaeed, Ibrahim Alsaeed, Mohamed Alsaeed. Recurrent Bacterial Meningitis in Paediatrics. American Journal of Pediatrics. Vol. 5, No. 3, 2019, pp. 98-103. doi: 10.11648/j.ajp.20190503.14

Received: May 23, 2019; Accepted: June 26, 2019; Published: July 4, 2019

\begin{abstract}
The number of studies about recurrent bacterial meningitis (RBM) diagnostic challenge in children is limited. Structural approach and early diagnosis of an underlying pathology are crucial to prevent further episodes and improve the overall outcome [1]. $1.3 \%$ of children with bacterial meningitis had experienced at least one previous episode. Anatomic abnormalities are the most common predisposing factor for RBM, and congenital inner ear malformation is the leading cause [2]. Acquired immune deficiency (HIV) forms an important cause of RBM in some areas [22]. Terminal Complement defect is the leading congenital immunodeficiency that may cause RBM [1]. History of head trauma is an important factor but should not lead to exclude other important factors. Isolation of a specific bacterial organism can guide the diagnostic approach. We want to report a case of recurrent bacterial meningitis in a 12 year old boy with a small nasal ethmoidal CSF- leak fistula activation after 6 years of a head trauma. A diagnostic approach has been suggested depending on review of many trusted studies and clinical experiences.
\end{abstract}

Keywords: Recurrent Bacterial Meningitis, Children, Microbiologic, Radiologic Diagnosis, Immunodeficiency, Mortality, Prognosis

\section{Introduction}

RBM by definition is two or more episodes of bacterial meningitis with at least 3 week interval after the completion of therapy for the initial episode, or any interval if caused by a different bacterial organism [1]. If the next episode is less than 3 weeks and caused by the same bacterial organism it can be relapse or recrudescence [3]. Cases of chronic meningitis, mycobacterial meningitis, and interventional therapy associated (like VP. Shunt and cochlear implant or any surgery on the face, skull, or spine) should be excluded from this definition. Recurrent bacterial meningitis is an uncommon phenomenon but generally poses a considerable diagnostic challenge. $1.3 \%$ of children with acute bacterial meningitis had experienced at least one previous occasion [3]. Mortality of RBM in many studies is less than $15 \%$, much less than mortality of the first episode of bacterial meningitis (25-34\%) [4].

\section{Predisposing Causes}

Predisposing factors for RBM can be divided to anatomical abnormalities, immunodeficiencies, and chronic parameningeal infections. Structural approach and early diagnosis of an underlying pathology are crucial to prevent further episodes and improve the overall outcome for the affected individual. A study conducted on 363 cases of recurrent bacterial meningitis described in 144 publications concluded that 214 cases $(59 \%)$ were related to anatomical problems, 132 cases $(36 \%)$ were related to immunological deficiencies, and 17 cases $(5 \%)$ were related to parameningeal infections. In $93 \%$ of anatomical abnormalities there was a defect in cranial or cervical region, only $7 \%$ has lumbosacral defect. $47 \%$ of anatomical abnormalities were secondary to trauma. Individuals with immunodeficiency were 55\% complement deficiency, 33\% HIV related, $13 \%$ immunoglobulin deficiency and asplenia. 
In the parameningeal infection group $73 \%$ related to chronic otitis media and/or mastoiditis, $12.5 \%$ related to sinusitis, $13.5 \%$ related to osteomyelitis [1].

Encephalomeningoceles are usually congenital and rare 1/11.500 of live births [5]. Basal encephaloceles could be Trans ethmoidal, spheno- ethmoidal, and Trans sphenoidal [6]. It may present as feeding or respiratory difficulties in the neonatal age, as nasal obstruction at any age in childhood, or as recurrent meningitis at any age. Interestingly, rhinorrhea in this group appears to be rare and occurs primarily after surgical interventions such as biopsy or polypectomy [6]. Patients with RBM should be tested for hearing loss for the possibility of inner ear malformations. For example, in Mondini dysplasia the cochlea consists of one and a half turns only and the vestibular structure is underdeveloped with a fistulous connection to the dural space. The likelihood of a patient with inner ear malformation acquiring meningitis appears to be high (25\%) and the majority of cases develop under 10 years of age [7]. Sea diving and preceding fall may contribute to fistula activation. High resolution CT- scanning of the temporal bones is the diagnostic method of choice [89]. Only $19 \%$ of cases of RBM have an underlying congenital immunodeficiency [1]. Complement deficiencies are generally associated with increased risk of bacterial infections and also linked to autoimmune disorders like SLE. Complements play an important role in the defense against encapsulated bacteria including Neisseria meningitis, Neisseria gonorrhea, Streptococcus pneumonia, and Haemophilus influenza [13]. 83\% of invasive meningococcal disease (meningitis/sepsis) cases had terminal complement deficiency (C5 to C9) [14].

Only a small proportion were cases of $\mathrm{C} 1$ to $\mathrm{C} 4$ or factors $\mathrm{H}$, I, P deficiency. Most individuals with terminal complement defect presented with the first bacterial meningitis in late childhood or early adulthood [15]. 12\% of X-linked agammaglobulinemia (Burton's disease) cases in USA experienced viral encephalitis and/or meningitis with enteroviruses like Echo, Coxsacki, Polio viruses. IgG subclass deficiencies are at increased risk of invasive bacterial infections in general and infection with Streptococcus Pneumonia and Haemophilus influenza in particular, especially recurrent respiratory and Sino pulmonary infections $[16,17]$. Combined $\operatorname{IgG} 2 / \operatorname{IgG} 4$ deficiency was the cause of RBM in 2 children [18].

IRAK-4 "an intracellular signal transporter protein of Tolllike receptor activation pathway" its deficiency can cause recurrent episodes of invasive bacterial infection since infancy but not viral nor fungal [19]. Acquired immunodeficiency (HIV) typically predisposes to Cryptococcal meningitis, and also to mycobacterial and bacterial meningitis [20]. Both children and adults with HIV have increased risk of acquiring pneumococcal infection [21]. In one study in Malawi $68 \%$ of RBM in children occurred in HIV positive children [22]. The risk of recurrence of meningitis in HIV positive children is six times higher than normal. Streptococcus pneumonia is the cause in $58 \%$, and salmonella in $32 \%$ [23].]. Congenital or post- surgical asplenia reported in 21 cases of RBM; 20 of them caused by streptococcus pneumonia [3].

Chronic parameningeal infections like Sinusitis, otitis media, and mastoiditis can result in central nervous system infections by direct spread and to lesser extent via the hematogenous route. The most common complication of sinusitis is orbital cellulitis followed by intracranial complications [24]. Frontal lobe abscess and Bacterial meningitis are the most common intracranial complications. Otitis media is far less commonly associated with intracranial complication $(0.24 \%)$ versus $3.7 \%$ for sinusitis; meningitis and brain abscesses are the most common complications [26]. Chronic osteomyelitis, Maffucci's syndrome and neurofibromatosis type 1 all had been documented as causes of RBM in children [27, 28]. Implicated organisms are: staphylococcus aureus, streptococcus pyogenes group A, pneumococcus, Haemophilus influenza, and anaerobes.

\section{Case Report}

\subsection{Early Discharge}

A 12 year old boy presented to the ER with fever, sore throat, and headache for one day. Physical examination was almost negative apart from mild congested throat for which he was diagnosed as viral upper respiratory infection and discharged home on simple symptomatic treatment. 6 hours later the child suffered generalized tonic clonic seizures and coma.

\subsection{First Admission}

Seizures persisted till the arrival of the ambulance team, and responded well to a single IV dose of diazepam. On arrival to the ER, he was unconscious, febrile, with very clear nuchal rigidity. No past medical history or family history, no past history of major trauma, no past admission history to hospital or seizures. Vaccine complete to age with four doses of PCV -13 valent pneumococcal conjugated vaccine. Growth and development were normal for age. W: $50 \mathrm{~kg}, \mathrm{H}$ : $155 \mathrm{~cm}$, BP: 140/75mmhg. Laboratory investigations:

Complete blood count: leukocytosis $25000 / \mathrm{mm}^{3}$; neutrophil $20,000 / \mathrm{mm}^{3}$; platelets count of $520,000 / \mathrm{mm}^{3} ; \mathrm{C}$ - reactive protein (CRP) level of $160 \mathrm{mg} / \mathrm{L}$ (normal range: $0-5 \mathrm{mg} / \mathrm{L}$ ). After proper stabilization treatment in ER "including ceftriaxone "the patient was admitted in PICU. Cranial Ct- scan was normal; Lumber Puncture CSF examination showed 380 polymorphonuclear leukocytes $/ \mathrm{mm}^{3}$; high Protein concentration of $330 \mathrm{mg} / \mathrm{dl}$; low glucose level of $11 \mathrm{mg} / \mathrm{dL}$; Blood sugar was $150 \mathrm{mg} / \mathrm{dl}$; Ionized calcium: $2.1 \mathrm{~m}$ mole/dl; Gram stain- CSF: gram positive diplococci; $\mathrm{CSF}-\mathrm{C} / \mathrm{s}$ : streptococcus pneumonia. Blood- C/S: negative; PCR for HSV: negative. As a case of acute bacterial meningitis, Ceftriaxone and vancomycin were administered for 14 days and he was discharged home after full clinical and laboratory recovery.

\subsection{Second Admission}

86 days after discharge, the patient visited the ER again 
complaining of fever, photophobia, headache, and neck stiffness. CSF and Blood tests revealed: CSF: 125 Leukocytes $/ \mathrm{mm}^{3}$-mostly polymorph- Protein $209 \mathrm{mg} / \mathrm{dl}$; and low glucose level $10 \mathrm{mg} / \mathrm{dl}$; CBC: leukocytes $22000 / \mathrm{mm}^{3}$; CRP $191 \mathrm{mg} / \mathrm{L}$. He was admitted again as a case of recurrent bacterial meningitis for treatment and further investigations. Gram stain-CSF: gram positive diplococci; C/S-CSF: streptococcus pneumonia susceptible to ceftriaxone and vancomycin. PCR -CSF for herpes simplex virus and tuberculosis was negative.

\subsection{Minor or Major Head Trauma}

When parents were asked again about head trauma specifically, they mentioned a head trauma during a bicycle accident 6 years ago; primary evaluation at that time in the ER was normal and he was discharged home as a case of minor head trauma. At this stage, Cranial MRI was done (as the best investigation for CSF -leak). It showed anterior basal skull defect, ethmoidal CSF- leak fistula, and frontal dural thickening.

Neurosurgeon was consulted and Dural plasty was performed after 3 weeks of parenteral antibiotic treatment with repeated laboratory investigations including CSF study all were normal. Repeated MRI after surgery was normal. Now the patient is symptom free after 2.5 years of surgery.

\section{Discussion}

\subsection{What Is the Cause}

$2 \%$ of all head injuries are associated with CSF leak. $28 \%$ of RBM are a result of CSF fistulas as a result of head injuries [25]. CSF- fistulas are most commonly associated with frontal sinuses fractures [10-11]. The diagnosis in children is more challenging as CSF rhinorrhea is often not recognized. Delays in rhinorrhea up to several years after trauma have been reported. The risk of bacterial meningitis is greatest in the first week after trauma (9.1\%) [12]. One patient with post traumatic ethmoidal fistula suffered 39 episodes of RBM over 20 years period [12]. 89\% of post trauma meningitis are caused by streptococcus pneumonia, $6 \%$ by Haemophilus Influenza, and $4 \%$ by Neisseria Meningitides [10-12].

Lumbosacral lesions including meningocele and dermoid cysts with dermal sinus almost universally presented in infancy. In contrast, children with cranial cervical, and thoracic dermal sinuses and /or dermoid cysts tend to present slightly later in early childhood [1]. Neuroenteric cyst present with RBM during the first 16 months of life. Mondini dysplasia and other inner ear anomalies experience first meningitis in the first 3 years and 93\% of all B.M. happened in childhood [7, 29, 30]. Cranial meningocele main age to present is 7 years. Ethmoidal or petrosal skull defects all patients presented before the age of 5 years. The majority of Complement deficiency cases experienced their first BM during childhood or early adulthood [31]. Intranasal meningocele may remain asymptomatic unless ruptured incidentally by trauma or interventional biopsy or polypectomy.

\subsection{Microbiological Aspects}

Repeated isolation of a particular bacterium can potentially point towards the underlying condition.

Streptococcus Pneumonia is the most common in: immunodeficiency, asplenia, chronic renal failure, and head injuries $[32,33,34]$. It is the most common isolated organism in all cases of abnormal CSF -fistula connections in cranial location $[35,28,36]$. It also the most common organism in $\mathrm{HIV}$, agammaglobulinemia, IgG subclass deficiency and early complement deficiency C2 to C4). [28].

Neisseria meningitides was seen in most types of complement deficiency; $41 \%$ of recurrent meningococcal infections had an underlying complement deficiency [37]. The vast majority $(92 \%)$ of recurrent meningitis with $\mathrm{N}$. meningitides occurred in patients with complement deficiency.

Haemophilus influenza -none type B- played a relatively small role in RBM especially in Neuroenteric cysts, and skull fractures. Staphylococcus aureus is relatively a rare cause; $80 \%$ of Staph. aureus meningitis had a known predisposing CNS abnormality; mainly VP shunts and meningoencephaloceles which could be intranasal. In the remaining, prematurity was the main risk. No Staphylococcus aureus was reported for any patient with immunodeficiency [38]. Only 3.6\% of BM were caused by gram negative enteric organisms GNEBM [39]. 26\% of patients had an underlying conditions mainly urinary tract anomalies and neural tube defects. Even a single episode of GNEBM should promote a search for CSF fistulas and urinary tract malformation and in rare cases chronic sinusitis [40].

\section{Approach to Recurrent Bacterial Meningitis}

\subsection{Detailed History}

It is essential to ask about major traumatic events for several years ago. However, its presence should not lead to the presumption that a basal skull fracture is necessarily the underlying cause. Such history of head trauma was obtained frequently from patients with a confirmed congenital defect [41]. Any persistent nasal discharge after trauma should be considered as rhinorrhea till proven otherwise [42]. Potential hearing impairment or speech delay should raise the suspicion of inner ear malformations. It is important not to assume that hearing impairment in children is simply due to preceeding episodes of meningitis. History of recurrent episodes of otitis media and/or mastoiditis may point toward a Para meningeal infection spread. A history of failure to thrive and recurrent infection may point to immunodeficiency, especially when there is other family members with recurrent or severe infections. 


\subsection{Physical Examination}

Careful observation for any cutaneous stigmata, dermal sinuses tract with particular attention to the head and spine. Skin scars of past abscesses, parotid enlargement, severe candidiasis, splenomegaly indicate immunodeficiency. Absence of lymph nodes and tonsils is seen in X-linked agammaglobulinemia. Anosmia and lor hyposmia in $41 \%$ of traumatic CSF- fistula [43]. CSF- leak; CSF- rhinorrhea mostly unilateral and increases with Valsalva maneuver or bending forward [1].

CSF-otorrhea may occur with inner ear mal formation or temporal bone defects. A bulging tympanic membrane with a visible fluid level should not be dismissed simply as serous otitis media. It could be the only sign of Otogenic-CSF-fistula [44]. Testing for Beta2 transferrin (protein) in nose and/or ear secretions has high specificity to CSF-leak. Hearing deficit and nasal meningocele or even the site of a CSF leak should be excluded by otolaryngologist [44].

\subsection{Laboratory Investigations}

1. culture and sensitivity of CSF and blood. Complete blood count, blood film (Howell- Jolly Bodies)

2. Immunoglobulins (Ig A-M-G-E-D).

3. IgG subclasses (IgG1, to IgG4).

4. CH50 for abnormalities of classical complement pathway (C1-C9) if it is low, it is indicated to evaluate the level of every complement.

5. AH50 for abnormalities of the alternative complement pathway.

6. HIV antibody test.

7. Levels of specific antibodies against particular antigens such as Tetanus, Diphtheria and Toxoid antibodies reflect the ability of the humoral immunity to generate appropriate response.

8. Lymphocyte subsets.

9. T-cell proliferation.

10. B -cell proliferation.

11. Neutrophil function tests.

\subsection{Radiological Investigations}

1. CT scan and High Resolution CT (HRCT) scans in particular produce the best definition of bony structures and inner ear malformations [45-46].

2. CT cisternography with injection of contrast medium via lumbar puncture can detect CSF- leak through a fistula or its presence in nasal sinuses.

3. MRI scan offers the best definition of brain and soft tissue. MRI sensitivity in detecting CSF-leak is considered by some experts to be $(100 \%)$ much more than the HRCT sensitivity (75\%) [47].

The use of diffusion-weighted MRI has an additional value to identify CSF- leak [48].

1. Radionuclide cisternography is helpful when CT and MRI scans fail to identify CSF - leak [48].

2. Tc $-99 \mathrm{~m}$ - DTPa scan (Diethylene Triamine Penta acetate). However this method cannot pinpoint the exact location of the defect.

3. Spinal ultrasound: in spinal and canal study, Ultra sound imaging and MRI are the most useful investigations to detect spina bifida and dermal sinuses [49-50]. Depending on the suspected site appropriate investigations should be chosen.

\section{Investigation Plan}

Some experts prefer to investigate for the underlying cause of RBM in two steps if needed [1]:

step 1:

1. CBC, blood Film

2. $\mathrm{C} / \mathrm{S}$ of blood, CSF, skin swabs, urine, ear and nose secretions.

3. $\mathrm{CH} 50$

4. Immunoglobulins, HIV antibodies.

5. Audiological assessment by otolaryngologist.

6. Abdominal and spinal U/S (asplenia and spina bifida). step 2:

1. Lymphocyte subtypes, and function.

2. AH50 for alternative complement.

3. Specific antibodies.

4. Cranial HRCT. And /or MRI-radionuclide cisternography if needed.

5. Spinal MRI.

\section{Conclusion}

Recurrent bacterial meningitis in children is a diagnostic challenge which needs a careful approach to discover the underlying cause. History of trauma may indicate the presence of acquired anatomical CSF leak, but it may enhance the presentation of congenital anomalies like nasal meningocele or inner ear dysplasia. Rhinorrhea is extremely rare in children even in the presence of confirmed nasal csf leak. The presence of transferrin beta in nasal or ear secretion has high specificity and sensitivity for CSF leak. Although the risk of bacterial meningitis decreases dramatically after the first week of head trauma, fistula may reactivate after many years with recurrent bacterial meningitis. It is important to ask about any memorable head trauma years ago no matter if it was considered minor or major. History of recent nasal Intervention or biopsy may indicate latent nasal fistula or meningocele rupture. Isolation of a specific microbial organism may indicate a specific underlying cause. Mortality rate of RBM episode is lower than that of acute Bacterial meningitis; $0-15 \%$ and $20-34 \%$ respectively. Anatomical abnormalities (congenital and/or acquired) are the most common predisposing factors for RBM, and Congenital inner ear malformation is the leading cause of RBM. Monidini dysplasia is the most common recognized inner ear malformation. [1-2]. Therefore, hearing lose in RBM should not be simply explained as a complication of meningitis. Chronic underlying immune deficiency is much less important cause 
of recurrent bacterial meningitis in children. Well planned investigation study in 2 step is recommended for all cases of RBM. However, if clear findings by history and physical examination may indicate a possible etiology, it might be excluded first using the recommended investigation as mentioned above.

\section{Abbreviations}

$\begin{array}{ll}\text { RBM } & \text { recurrent bacterial meningitis } \\ \text { CSF } & \text { cerebral spinal fluid } \\ \text { HIV } & \text { human immune deficiency virus } \\ \text { VP. shunt } & \text { ventricular peritoneal shunt } \\ \text { PICU } & \text { pediatric intensive care } \\ \text { C/S } & \text { Culture and sensitivity } \\ \text { W } & \text { Weight } \\ \text { H } & \text { Height } \\ \text { BP } & \text { Blood Pressure } \\ \text { ER } & \text { emergency room } \\ \text { CNS } & \text { central nervous system } \\ \text { GNEBM } & \text { gram negative enteric bacterial meningitis } \\ \text { SLE } & \text { systemic lupus erythematosus } \\ \text { PCR } & \text { polymerase chain reaction } \\ \text { HSV } & \text { herpes simplex virus } \\ \text { MRI } & \text { magnetic resonance imaging. }\end{array}$

\section{References}

[1] Marc Tebruegge, Nigel Curtis. epidemiology, etiology, pathogenesis, and diagnosis of recurrent bacterial meningitis. American society for microbiology Journal, January, 2009. DOI: 10.1128/CMR.00009-08.

[2] Eda Kepenekli, Ayse Karaasla, Murat Sari. Recurrent bacterial meningitis in a child with Mondini dysplasia. Case Reports in Pediatrics volume 2014 Article ID 364657. Marc Tebruegge, Nigel Curtis., Epidemiology, etiology, pathogenesis and diagnosis of recurrent bacterial meninigitis. clinical microbiology review, July 2008, p. 519-537 DOI: 10.1128/CMR.00009-08.

[3] Drummond, D. S., A. L. de Jong, C. Giannoni, M. Sulek, and E. M. Friedman. 1999. Recurrent meningitis in the pediatric patient - the otolaryngologist'srole. Int. J. Pediatr. Otorhinolaryngol. 48: 199-208.

[4] van de Beek, D., J. de Gans, L. Spanjaard, M. Weisfelt, J. B. Reitsma, andM. Vermeulen. 2004. Clinical features and prognostic factors in adults with bacterial meningitis. N. Engl. J. Med. 351: 1849-1859.

[5] Izquierdo, J. M., and L. M. Gil-Carcedo. 1988. Recurrent meningitis andtransethmoidal intranasal meningoencephalocele. Dev. Med. Child Neurol. 30: 248-251.

[6] Whittet, H. B., S. Barker, P. Anslow, and S. Leighton. 1990. Heterotopicbrain tissue: a rare cause of adult recurrent meningitis. J. Laryngol. Otol. 104: 328-330.

[7] Phelps, P. D., A. King, and L. Michaels. 1994. Cochlear dysplasia and meningitis. Am. J. Otol. 15: 551-557.

[8] Michel, R. S., E. DeFlora, J. Jefferies, and L. G. Donowitz.
1992. Recurrent meningitis in a child with inner ear dysplasia. Pediatr. Infect. Dis. J. 1.

[9] Tien-HauLien Chun-MinFu et al. 2011. Recurrent Bacterial Meningitis Associated with Mondini Dysplasia. J. Pediatrics and Neonatology, 52.5: 294-296.

[10] Brodie, H. A., and T. C. Thompson. 1997. Management of complications from 820 temporal bone fractures. Am. J. Otol. 18: 188-197, 336-338.

[11] Friedman, J. A., M. J. Ebersold, and L. M. Quast. 2000. Persistent post traumatic cerebrospinal fluid leakage. Neurosurg. Focus 9: e1.

[12] Eljamel, M. S., and P. M. Foy. 1990. Acute traumatic CSF fistulae: the risk of intracranial infection. Br. J. Neurosurg. 4: 381-385. 53 .

[13] Figueroa, J. E., and P. Densen. 1991. Infectious diseases associated with complement deficiencies. Clin. Microbiol. Rev. 4: 359-395.

[14] Russell, T., and B. H. Cummins. 1984. Cerebrospinal fluid rhinorrhea 34 years after trauma: a case report and review of the literature. Neurosurgery, 15: 705-706.

[15] Platonov, A. E., V. B. Beloborodov, and I. V. Vershinina. 1993. Meningococcal disease in patients with late complement component deficiency: studies in the U.S.S.R. Medicine (Baltimore) 72: 374-392.

[16] Freijd, A., V. A. Oxelius, and B. Rynnel-Dagoo. 1985. A prospective studdemonstrating an association between plasma IgG2 concentrations and susceptibility to otitis media in children. Scand. J. Infect. Dis. 17: 115-120.

[17] Shackelford, P. G., S. H. Polmar, J. L. Mayus, W. L. Johnson, J. M. Corry, and M. H. Nahm. 1986. Spectrum of IgG2 subclass deficiency in children with recurrent infections: prospective study. J. Pediatr. 108: 647-653.

[18] Harfi, H. A., M. Abdul-Jabbar, and E. Rabe. 1989. Recurrent meningitis associated with congenital deafness and IgG subclass immunodeficiency: report of a case. Ann. Saudi Med. 9: 494-496.

[19] Medzhitov, R., P. Preston-Hurlburt, E. Kopp, A. Stadlen, C. Chen, S. Ghosh, and C. A. Janeway, Jr. 1998. MyD88 is an adaptor protein in the hToll/IL-1 receptor family signaling pathways. Mol. Cell 2: 253-258.

[20] Jarvis, J. N., and T. S. Harrison. 2007. HIV-associated cryptococcal meningitis. AIDS 21: 2119-2129.

[21] Bernstein, L. J., B. Z. Krieger, B. Novick, M. J. Sicklick, and A. Rubinstein. 1985. Bacterial infection in the acquired immunodeficiency syndrome of children. Pediatr. Infect. Dis. 4: $472-475$.

[22] Molyneux, E. M., M. Tembo, K. Kayira, L. Bwanaisa, J. Mweneychanya, A. Njobvu, H. Forsyth, S. Rogerson, A. L. Walsh, and M. E. Molyneux. 2003. The effect of HIV infection on paediatric bacterial meningitis in Blantyre, Malawi. Arch. Dis. Child. 88: 1112-1118.

[23] Kourtis, A. P., P. Bansil, S. F. Posner, C. Johnson, and D. J. Jamieson. 2007. Trends in hospitalizations of HIV-infected children and adolescents in the United States: analysis of data from the 1994-2003 Nationwide Inpatient Sample. Pediatrics 120: e236-243. 
[24] Clayman, G. L., G. L. Adams, D. R. Paugh, and C. F. Koopmann, Jr. 1991. Intracranial complications of paranasal sinusitis: a combined institutional review. Laryngoscope 101: 234-239.

[25] Weiss, A., D. Friendly, K. Eglin, M. Chang, and B. Gold. 1983. Bacterial periorbital and orbital cellulitis in childhood. Ophthalmology 90: 195-203.

[26] Avasthi, G., A. Parti, S. N. Gupta, and R. Goel. 1991. Frontal bone osteomyelitis causing recurrent meningitis. J. Assoc. Physicians India 39: 409-410.

[27] Kragsbjerg, P., and H. Rydman. 2001. Recurrent pneumococcal bacteraemia and meningitis in an asplenic adult with possible unusual focus. Scand. J. Infect. Dis. 33: 706708 .

[28] Chapman, P. H., H. D. Curtin, and M. J. Cunningham. 2000. An unusual pterygopalatine meningocele associated with neurofibromatosis type 1. Case report. J. Neurosurg. 93: 480483.

[29] Phelps, P. D., D. Proops, S. Sellars, J. Evans, and L. Michaels. 1993. Congenital cerebrospinal fluid fistula through the inner ear and meningitis. J. Laryngol. Otol. 107: 492-495.

[30] Rupa, V., V. Rajshekhar, and D. J. Weider. 2000. Syndrome of recurrent meninigit is due to congenital perilymph fistula with two different clinical presentations. Int. J. Pediatr. Otorhinolaryngol. 54: 173-177.

[31] Maitra, S., and S. K. Ghosh. 1989. Recurrent pyogenic meningitis - a retrospective study. Q. J. Med. 73: 919-929.

[32] Fijen, C. A., E. J. Kuijper, A. J. Hannema, A. G. Sjoholm, and J. P. van Putten. 1989. Complement deficiencies in patients over ten years old with meningococcal disease due to uncommon serogroups. Lancet ii: 585-588.

[33] Levine, O. S., M. Farley, L. H. Harrison, L. Lefkowitz, A. McGeer, and B. Schwartz. 1999. Risk factors for invasive pneumococcal disease in children: a population-based casecontrol study in North America. Pediatrics 103: E28.

[34] McGregor, D. H., R. Cherian, J. J. Kepes, and M. Kepes. 1994. Case reports: heterotopic brain tissue of middle ear associated with cholesteatoma. Am. J. Med. Sci. 308: 180 183.

[35] Bernstein, J. M., J. T. Roland, and M. S. Persky. 1997. Sphenoid cranial base defects in siblings presenting with cerebrospinal fluid leak. Skull Base Surg. 7: 193-197.

[36] Dhar, M. C., S. Chaudhuri, K. Basu, S. Pain, T. J. Sau, and K. Mitra. 2001. Recurrent pyogenic meningitis in a case of transethmoid encephalocele. J. Assoc. Physicians India 49: 767-768.
[37] Nielsen, H. E., C. Koch, P. Magnussen, and I. Lind. 1989. Complement deficiencies in selected groups of patients with meningococcal disease. Scand. J. Infect. Dis. 21: 389-396.

[38] Hasegawa, T., N. Sugeno, Y. Shiga, A. Takeda, H. Karibe, T. Tominaga, and Y. Itoyama. 2005. Transethmoidal intranasal meningoencephalocele in an adult with recurrent meningitis. J. Clin. Neurosci. 12: 702-704.

[39] Unhanand, M., M. M. Mustafa, G. H. McCracken, Jr., and J. D. Nelson. 1993. Gram-negative enteric bacillary meningitis: a twenty-one-year experience. J. Pediatr. 122: 15-21.

[40] Vieira, T., S. C. Eppes, and G. Magram. 1996. Recurrent E. coli meningitis associated with an intracranial dermoid cyst. Clin. Pediatr. (Philadelphia) 35: 32-33.

[41] Lieb, G., J. Krauss, H. Collmann, L. Schrod, and N. Sorensen. 1996. Recurrent bacterial meningitis. Eur. J. Pediatr. 155: 2630.

[42] Amin, M. U., and A. Ghaffar. 2006. Delayed appearance of posttraumatic cerebrospinal fluid fistula. J. Coll. Physicians Surg. Pak. 16: 378-380.

[43] Laun, A. 1982. Traumatic cerebrospinal fluid fistulas in the anterior andmiddle cranial fossae. Acta Neurochir. (Wien) 60: 215-222.

[44] Bektas, D., R. Caylan, O. Bahadir, and R. Caylan. 2007. Occult anterior skull base defect without rhinorrhea as a cause of recurrent meningitis. Surg. Neurol. 68: 50-52.

[45] Lloyd, M. N., P. M. Kimber, and E. H. Burrows. 1994. Posttraumatic cerebrospinal fluid rhinorrhoea: modern highdefinition computed tomography is all that is required for the effective demonstration of the site of leakage. Clin. Radiol. 49: $100-103$.

[46] Meco, C., and G. Oberascher. 2004. Comprehensive algorithm for skull base dural lesion and cerebrospinal fluid fistula diagnosis. Laryngoscope 114: 991-999.

[47] Johnson, D. B., P. Brennan, J. Toland, and A. J. O'Dwyer. 1996. Magnetic resonance imaging in the evaluation of cerebrospinal fluid fistulae. Clin. Radiol. 51: 837-841.

[48] Levy, L. M., A. J. Gulya, S. W. Davis, D. LeBihan, S. S. Rajan, and D. Schellinger. 1995. Flow-sensitive magnetic resonance imaging in the evaluation of cerebrospinal fluid leaks. Am. J. Otol. 16: 591-596.

[49] Korsvik, H. E., and M. S. Keller. 1992. Sonography of occult dysraphism in neonates and infants with MR imaging correlation. Radiographics 12: 297-306; discussion, 307-308.

[50] Lowe, L. H., A. J. Johanek, and C. W. Moore. 2007. Sonography of the neonatal spine: part 2, spinal disorders. Am. J. Roentgenol. 188: 739-744. 